\title{
Simultaneous estimation of unknown parameters using a-priori knowledge for the estimation of interfacial heat transfer coefficient during solidification of $\mathrm{Sn}-5 \mathrm{wt} \% \mathrm{~Pb}$ alloy-an $\mathrm{ANN}$-driven Bayesian approach
}

\author{
P S VISHWESHWARA, N GNANASEKARAN* and M ARUN \\ Department of Mechanical Engineering, National Institute of Technology Karnataka, Surathkal, Mangalore, \\ Karnataka 575025, India \\ e-mail: gnanasekaran@ nitk.edu.in
}

MS received 18 July 2018; revised 25 November 2018; accepted 28 December 2018; published online 30 March 2019

\begin{abstract}
The present methodology focuses on model reduction in which the prevalent one-dimensional transient heat conduction equation for a horizontal solidification of $\mathrm{Sn}-5 \mathrm{wt} \% \mathrm{~Pb}$ alloy is replaced with Artificial Neural Network (ANN) in order to estimate the unknown constants present in the interfacial heat transfer coefficient correlation. As a novel approach, ANN-driven forward model is synergistically combined with Bayesian framework and Genetic algorithm to simultaneously estimate the unknown parameters and modelling error. Gaussian noise is then added to the temperature distribution obtained using the forward approach to represent real-time experiments. The hallmark of the present work is to reduce the computational time of both the forward and the inverse methods and to simultaneously estimate the unknown parameters using a-priori engineering knowledge. The results of the present methodology prove that the simultaneous estimation of unknown parameters can be effectively obtained only with the use of Bayesian framework.
\end{abstract}

Keywords. Casting; GA; least squares; Bayesian; inverse; ANN.

\section{Introduction}

A numerical solution that involves a mathematical model provides a complete insight of solidification problem that helps in obtaining quality casting products. A fine numerical model yields an accurate prediction of temperature distribution inside the solidification domain close to the experimental data. In order to solve numerically, it is necessary to know all input parameters affecting the solution significantly. The boundary condition at the mold-metal interface referred to as interfacial heat transfer coefficient (IHTC) plays an important role in controlling the solidification and development of microstructure [1]. During solidification of molten metal, liquid metal shrinks and an air gap exists at mold-metal interface due to the release of heat to the mold. This creates a resistance to the heat transfer to the mold referred to as IHTC. The value of IHTC also depends on various parameters such as direction of solidification [2, 3], mold materials and mold coating [4, 5], surface roughness [6-8], pressure [9, 10], casting geometry, type of casting, etc. Many researchers explained the formation of air gap at the mold-metal interface with the assistance

*For correspondence of displacement meters to estimate the values of IHTC $[11,12]$. The thermal field in the solidification domain is very sensitive to the IHTC values [13]. As information about the casting and mold surfaces is unknown, locating thermocouples at the mold-metal interface will distort the thermal field. An accurate estimation can be performed by inverse methods where the unknown parameters are estimated with the help of temperatures at several locations in the domain. Beck's nonlinear estimation is the popularly used method to estimate the surface heat flux or heat transfer coefficients with the aid of temperature measurements available inside the problem domain [14]. A guess value of the unknown parameter is initialized and in every iteration, the error between the measured and the calculated temperatures is minimized using least squares. The methodology considers the sensitivity coefficients for each measurement location during the estimation procedure. Rajaraman and Velraj [15] compared two different methods, Beck's algorithm and control volume approach, to obtain the IHTC values for aluminium and sand mold. A deviation of $57 \%$ in the values of IHTC between the two methods was found. Arunkumar et al [16] estimated the heat flux variation spatially at the metal-mold interface due to mold filling using a Serial IHCP algorithm. Sun and Chao [17] used lumped capacitance method to 
find the IHTC values for $\mathrm{Sn}-20 \mathrm{wt} \% \mathrm{~Pb}$ alloy and A356 alloy against green sand mold.

Apart from popularly used Beck's inverse method, stochastic methods like Genetic algorithm (GA), Particle Swarm Optimization and Artificial Neural Network (ANN) are gaining a huge scope to solve inverse problems. With stochastic method, the solution will not get trapped in the local minima but the estimation procedure is time consuming. Generally, gradient-based methods have faster convergence compared with the evolutionary algorithms. The observations from the works of $[18,19]$ show that GA is immune to sensitivity coefficients and prove the robustness of the algorithm compared with the conventional sequential functional method. The results also depend on the temperature sensor locations and the future time steps considered to obtain the stable results. Though the GA is computationally expensive, it is capable of providing good results for the problems that are unstable or do not converge [20]. Wong and Pao [21] used GA to optimize the IHTC for casting geometry. The works of Ranjbar et al [22] and Dousti et al [23] emphasise the successful estimation of IHTC for noisy temperature data. The time of inverse estimation was found to be $8-9 \mathrm{~h}$. Vasileiou et al performed several simulations for varying casting geometry using ProCAST assuming the IHTC correlation with temperature as stepwise and exponential as well as stepwise function of time using experimental temperatures to estimate IHTC. The computational time required was around $10 \mathrm{~h}$ using GA to complete the overall estimation [24]. The application of PSO algorithm for determining IHTC for a continuous casting process shows that precise estimation is obtained with the use of measurement data from experiments [25]. Some research works show that the use of ANN as inverse method can remarkably overcome the computational cost. Zhang et al [26] used ANN as inverse method and the estimated IHTC was validated with a commercial software. The use of evolutionary algorithms is computationally expensive as observed in the afore-mentioned literatures. Therefore, a combination of neural network with evolutionary algorithm has been found to drastically reduce the computational cost. ANN can serve as a fast forward model ensuring a reduction in computational time for the inverse approach [27, 28]. Chanda et al [29] used combined ANNGA to estimate the thermal conductivities of composite materials and close agreements between simulated and experimental temperatures were observed. Ghadimi et al [30] estimated the unknown heat flux in a braking disc using ANN and sequential method where the stability of the results was dependent on the future time steps and the location of the sensors. The use of hybrid ANN in various heat transfer applications can be seen in [31-33]. The choice of objective function also decides the accuracy of the estimation. Usually, the selection of regularization term is crucial in obtaining accurate inverse solutions [34]. Shan and Shan used regularization method to estimate the IHTC values for ZL102 casting, which supports the fact that the regularization method provides effective solution by overcoming the ill-posed inverse problem [35]. Mota et al [36] applied Bayesian approach with Markov chain Monte Carlo (MCMC) for a one-dimensional nonlinear heat conduction problem to simultaneously estimate the heat flux and thermal parameters. Yan et al [37] used Bayesian framework for the estimation of Robin coefficient with the help of temperatures available at the boundaries. The results from the Bayesian framework in conjunction with Markov random field (MRF)-MCMC showed the ability in providing solutions with the uncertainties quantified. Different sampling techniques for the use of Bayesian framework prove the efficiency in retrieving the thermophysical properties using inverse method [38]. The results from the work of Deng and Hwang [39] give evidence that the Bayesian method delivers the best training method with the back propagation algorithm.

Based on the afore-mentioned literature, evolutionary algorithms are finding a new scope in the area of inverse problems because of their robustness and capability to provide stable solutions. The gradient-based methods with the least squares determine the unknowns without the quantification of uncertainties in the inverse results. In order to circumvent the difficulties of the afore-mentioned methods, in the present study, an attempt is made to exhibit the potential of Bayesian framework in estimating IHTC during the solidification of casting. The a-priori information, which is provided as a prior distribution, in Bayesian framework acts as an inherent regularization term, thus leading to well-posedness of the proposed inverse problem. Normally, the MCMC method used to explore the sample space within the Bayesian framework is time consuming [40, 41]. Therefore, the novelty of the present paper is to simultaneously estimate the constants appearing in the IHTC along with modelling error $(M E)$ associated with the temperature measurements, which is not reported hitherto in literature. Needless to say, in this paper, to obtain a feasible and quick solution, ANN-GA is applied with the Bayesian framework for the benefit of computations and uncertainty.

\section{Problem statement}

\subsection{Forward model}

A mold cavity of length $110 \mathrm{~mm}$ with $60 \mathrm{~mm}$ low-carbon steel chill is considered for solving horizontal solidification of $\mathrm{Sn}-5 \mathrm{wt} \% \mathrm{~Pb}$ alloy casting as shown in figure 1 . The main purpose of the design was to ensure a unidirectional solidification. The heat transfer exists mainly between the casting and chill with the provision of sufficient insulation around the mold cavity. The insulation prevents heat loss through the wall surroundings and the steel chill initiates the solidification in the horizontal direction. The effects of flow of the molten metal inside the mold are neglected. As 


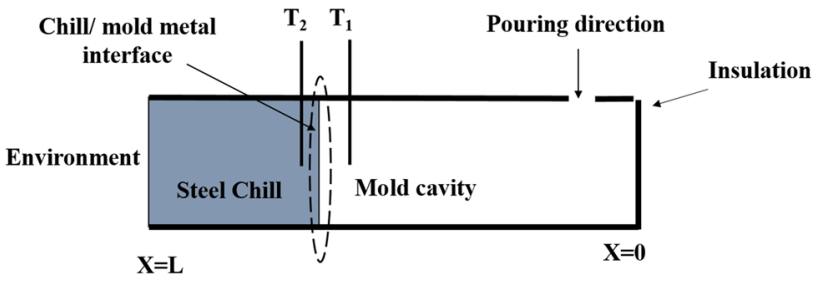

Figure 1. Schematic representation of the cast mold system.

the area of the air gap at the mold-metal interface is very small, the heat transfer at the mold-metal interface is assumed to happen only by conduction and the effects of convection and radiation are neglected. Two temperature sensors $T_{1}$ and $T_{2}$, one placed inside the mold cavity at a distance of $20 \mathrm{~mm}$ and other $3 \mathrm{~mm}$ in the steel chill, respectively, from mold-metal interface are used to measure the temperatures [42]. The domain is discretized as shown in figure 2 . The cast surface node $T_{C}$ and chill surface node $\mathrm{T}_{M}$ at the mold-metal interface are represented by subscripts ig and ig +1 , respectively.

The average IHTC $h_{i}$ in $\mathrm{W} /\left(\mathrm{m}^{2} \mathrm{~K}\right)$ at the mold-metal interface is given by

$$
h_{i}=\frac{q}{T_{C}-T_{M}}
$$

where $q$ is the average heat flux across the mold-metal interface in $\mathrm{W} / \mathrm{m}^{2}$ and $T_{C}$ and $T_{M}$ are the casting and chill surface temperatures $\left({ }^{\circ} \mathrm{C}\right)$, respectively.

The average heat flux given in Eq. (1) at the mold-metal interface is calculated using the temperature gradient at the surface and sub surface nodes:

$$
q=-k \frac{d T}{d x}=-k \frac{T_{m}^{p}-T_{m-1}^{p}}{d x}
$$

where $k$ is the thermal conductivity of the material (W/ $(\mathrm{mK}))$. Heat transfer occurs mainly by conduction and whatever heat flux that is released by casting is assumed to be equal to the heat flux received by the mold.

2.1a Governing equation for heat transfer in the mold: The unsteady one-dimensional heat conduction equation is given as follows:

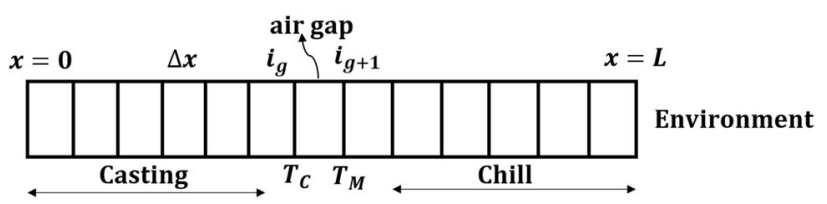

Figure 2. Discretization of the mold and metal interface.

$$
\frac{\partial^{2} T}{d x^{2}}=\frac{1}{\alpha} \frac{\partial T}{d t}
$$

where $T$ is the temperature in ${ }^{\circ} \mathrm{C}, t$ is the time in seconds and $\alpha$ is the thermal diffusivity in $\mathrm{m}^{2} / \mathrm{s}$ :

$$
\alpha=\frac{k}{\rho C_{p}}
$$

where $k$ is the thermal conductivity in $\mathrm{W} /(\mathrm{mK}), \rho$ is the density in $\mathrm{kg} / \mathrm{m}^{3}$ and $C_{p}$ is the specific heat capacity in $\mathrm{J} /$ $(\mathrm{kgK})$.

$2.1 \mathrm{~b}$ Governing equation for the heat flow in the casting: In a similar manner, the governing equation for heat transfer in the casting contains heat source term added to the left hand side of Eq. (3):

$$
k \frac{\partial^{2} T}{d x^{2}}+\ddot{q}=\rho C \frac{\partial T}{d t} .
$$

The heat source term $\ddot{q}$ takes the latent heat of solidification into account given by Eq. (6):

$$
\ddot{q}=\rho l \frac{d f_{s}}{d t}
$$

where $l$ is the latent heat and $f_{s}$ is the solid fraction of the casting. A linear form of $f_{s}$ term in the freezing range $T_{s} \leq T \leq T_{l}$ is assumed as shown in Eq. (7):

$$
f_{s}=\frac{T_{l}-T}{T_{l}-T_{s}}
$$

where $T_{l}$ and $T_{s}$ are, respectively, the liquidus and solidus temperature of the casting material. The value of $f_{s}$ varies between 0 and 1: $f_{s}=1$ for $T<T_{s}$ and $f_{s}=0$ for $T>T_{l}$.

The term $\frac{d f_{s}}{d t}$ in Eq. (6) can be related to temperature as $\frac{d f_{s}}{d t}=\frac{d f_{s}}{d T} \frac{d T}{d t}$ and substituted back to Eq. (5). The governing equation takes the final form shown in Eq. (9):

$$
k \frac{\partial^{2} T}{d x^{2}}=\rho C \frac{\partial T}{d t}-\rho l \frac{d f_{s}}{d T} \frac{d T}{d t} .
$$

Hence

$$
k \frac{\partial^{2} T}{d x^{2}}=\rho C^{\prime} \frac{\partial T}{d t}
$$

where

$$
C^{\prime}=C-l \frac{d f_{s}}{d T}
$$

2.1c Boundary conditions: At $x=0, \frac{d T_{C}}{d x}=0$.

At $x=i_{g}$ (casting surface), $-k_{C} \frac{d T_{C}}{d x}=h_{i}\left(T_{C}-T_{M}\right)$.

At $x=i_{g+1}$ (chill surface), $-k_{M} \frac{d T_{M}}{d x}=h_{i}\left(T_{C}-T_{M}\right)$;

At $X=L$ (chill environment), $=h_{a}\left(T_{M}-T_{\infty}\right)$. 
Table 1. Thermophysical properties of the $\mathrm{Sn}-5 \mathrm{wt} \% \mathrm{~Pb}$ alloy and low-carbon steel materials [42].

\begin{tabular}{|c|c|c|c|c|c|c|c|c|c|c|c|}
\hline Properties & $k_{s}$ & $k_{l}$ & $C_{s}$ & $C_{l}$ & $\rho_{s}$ & $\rho_{l}$ & $T_{l}$ & $T_{s}$ & $T_{f}$ & $K_{p}$ & $l$ \\
\hline $\mathrm{Sn}-5 \mathrm{wt} \% \mathrm{~Pb}$ & 64 & 33 & 221 & 259 & 7720 & 7380 & 216 & 183 & 232 & 0.0656 & 57120 \\
\hline Low-carbon steel & 46 & & 7860 & & 527 & & & & & & \\
\hline
\end{tabular}

2.1d Initial condition: At $t=0, T=T_{i}$ where $k_{M}$ is thermal conductivity of chill in $\mathrm{W} /(\mathrm{mK}), k_{C}$ is thermal conductivity of casting in $\mathrm{W} /(\mathrm{mK}), h_{i}$ is IHTC in $\mathrm{W} /\left(\mathrm{m}^{2} \mathrm{~K}\right), h_{a}$ is chill-environment heat transfer coefficient in $\mathrm{W} /\left(\mathrm{m}^{2} \mathrm{~K}\right), T_{i}$ is the initial temperature of the cast and mold in ${ }^{\circ} \mathrm{C}$ and $T_{\infty}$ is the ambient temperature in ${ }^{\circ} \mathrm{C}$.

Table $1^{1}$ reports the thermophysical properties of the materials. The initial temperatures of casting and chill were assumed as 256 and $27^{\circ} \mathrm{C}$, respectively. The IHTC $\left(h_{i}\right)$ is assumed to vary with time as power law shown in Eq. (11):

$$
h_{i}=a t^{-b} \text {. }
$$

The values of $h_{i}$ and $h_{a}$ are assumed based on available literature data [42] as mentioned in Eq. (12):

$$
h_{i}=18000 t^{-0.47} \text { and } h_{a}=5.7 t^{0.15} \text {. }
$$

The solution of the direct problem (forward model) is obtained by solving the governing equations subjected to the known initial and boundary conditions using an Explicit Finite Difference method that provides the temperature distribution inside the casting and mold. The value of the grid size $\Delta x=1 \mathrm{~mm}$ and the time step size is chosen to be 2 ms. Solving the Eqs. (3)-(10) along with the boundary conditions, the exact temperatures are obtained. Gaussian white noise is added to these exact temperatures such that $\sigma=0.01 T_{\max }, \sigma=0.02 T_{\max }$ and $\sigma=0.03 T_{\max }$ as shown in Eq. (13), as the experimental temperatures are usually subjected to errors. In order to mimic real-time experiments, the simulated measurements are represented as

$$
Y_{i M}=T_{\text {exact }}\left(t_{i}, \text { sensor }_{M}\right)+\epsilon \sigma
$$

where $M$ is the number of sensors, $\sigma$ is the standard deviation of the temperature measurements and $\epsilon$ is a random number varying between -2.576 and 2.576 for normally distributed errors with zero mean and $99 \%$ confidence bounds. The term $\epsilon \sigma$ represents the temperature measurement error [23]. The noisy data are now considered as simulated measurements $Y_{i M}$, which in turn are used to solve the inverse problem.

${ }^{1} \mathrm{SI}$ units: $T-{ }^{\circ} \mathrm{C}, \rho-\mathrm{kg} / \mathrm{m}^{3}, C-\mathrm{J} /(\mathrm{kgK}), k-\mathrm{W} /(\mathrm{mK}), \quad l-\mathrm{J} / \mathrm{kg}$; suffix: $l$ liquidus, $s$-solidus, $f$-fusion.

\section{Neural network}

Neural network is an artificial intelligence tool developed based on the biological nervous system. It links a relationship between the inputs and outputs with the help of weighted functions. Figure 3 shows insight of layers associated in ANN. ANN consists of input, hidden and output layers. Initially, the input and output data are segregated as training and testing data to form a network, which undergoes training until the error is reasonably less. The basic unit of the network is a neuron that is interlinked by layers that carry signals, which have to be processed. The weighted functions provide the strength for the signals to pass through the neurons. The trained network developed provides an output for a given input and hence helps in fast computation. In other words, the trained network provides the temperature distribution for any set of input parameters specified within the range. In the present work, the input layers consist of a set of assumed range of constants of the $h_{i}$ correlation as given in Eq. (11) and the output layers consist of corresponding temperature array at the given location from the available training data. Two hidden layers are created and the learning process is directed by feed forward back propagation algorithm. Feed forward back propagation neural network changes the weights in such a way that output vector produces the result that is closer to the target data. The output of ANN is fed in to the objective function to estimate the unknown parameters by inverse method. In the beginning, the input parameters are initialized to solve the forward model. In Eq. (11), $a$ and $b$ are the unknown parameters, within the specified range of $a=$ [100030000] and $b=[0.30 .6]$; large sets of numerical simulations are performed to generate data for neural network and the temperature measurements of the sensor at the

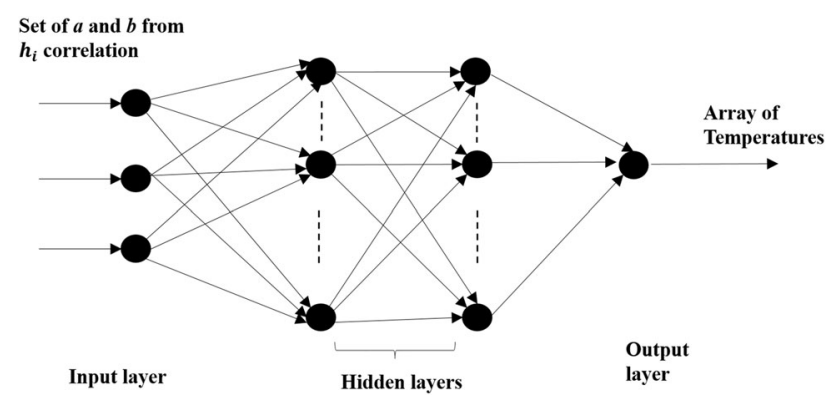

Figure 3. Representation of ANN. 

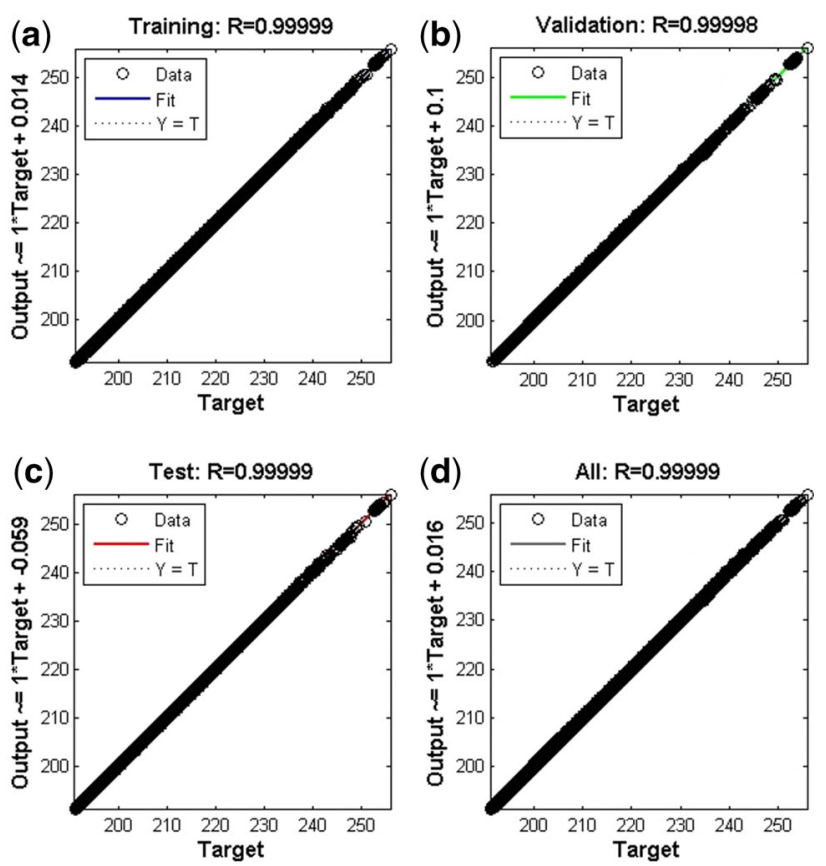

Figure 4. Regression plot between the output and target data: (a) training, (b) validation, (c) testing and (d) overall.

location $20 \mathrm{~mm}$ inside the casting for $150 \mathrm{~s}$ are used for developing the trained network. For this, $70 \%$ data were used for training and 30\% data were used for testing; 50 neurons were selected to produce a good fit between the output and the target data as shown in figure 4 . The trained network is referred to as fast forward model due to its robustness in producing the temperature data for any values of $a$ and $b$ within the specified range.

\section{GA as inverse method}

GA is a nature-based optimization algorithm developed by Holland and Goldberg and is extensively used due to its robustness in producing the results [43]. GA works on the principle of survival of the fittest proposed by Charles Darwin. The solution to a given problem is the one who survives in generation and the weaker ones are ignored. Initially, a set of population called as number of chromosomes is randomly initialized. Every chromosome is made up of genes, which represent bit strings. The randomly generated chromosomes are used to calculate the fitness function/objective function values and are ranked based on the type of problem (to maximize or minimize). The ranking helps in preserving the best individual for the next iteration. Later, the chromosomes undergo crossover, a process where chromosomes are randomly swapped at random crossover sites to produce new offsprings. This new set of chromosomes has a great tendency to produce good performance in retrieving the solution. In order to prevent the solution getting trapped in local minima/maxima, the

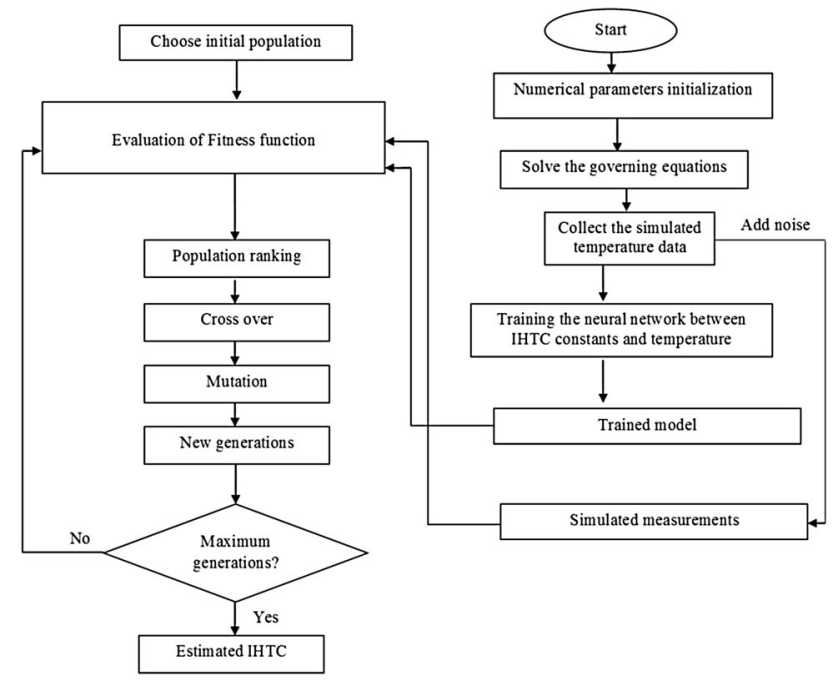

Figure 5. Overview of the present work.

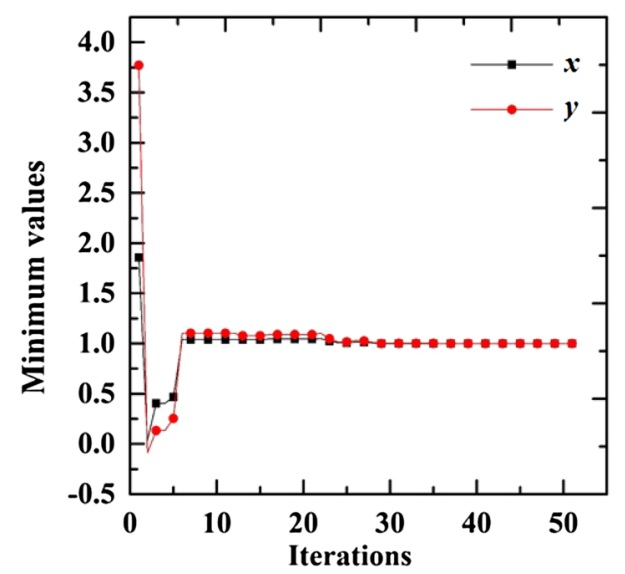

Figure 6. Minimum values of Rosenbrock banana function.

mutation process is carried out. Thus the newly produced population is used to find the fitness function and the process continues until the stopping criterion is reached.

As mentioned earlier, GA is used as an inverse method. For the purpose of demonstration, the retrieval methodology is attempted using least squares method (LSM). However, eventually it has been identified that the methodology fails to obtain proper results when the temperature data contain more noise, which will be discussed in the later section. The solution to the unknown parameter estimation using the least squares is achieved by minimizing the difference between the measured and the calculated temperatures obtained by the fast forward model [44] as shown in Eq. (14):

$$
S\left(h_{i}\right)=\sum_{m=1}^{M} \sum_{i=1}^{N}\left[Y_{i m}-T_{i m}\left(h_{i}\right)\right]^{2}
$$




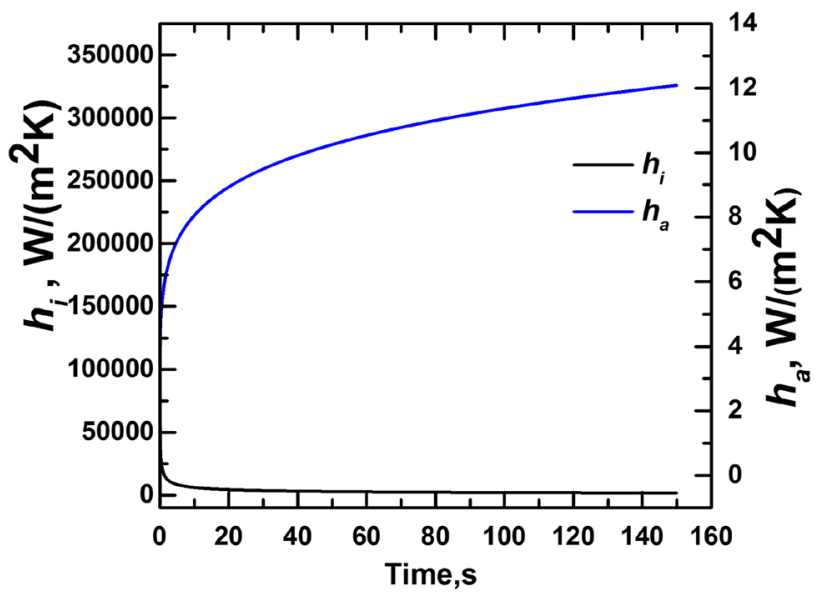

Figure 7. IHTC $\left(h_{i}\right)$ and chill-environment heat transfer coefficient $\left(h_{a}\right)$ used to solve the forward problem.

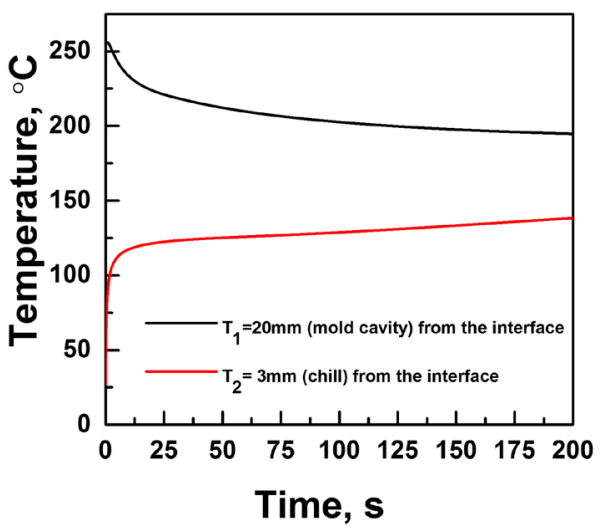

Figure 8. Temperatures at the locations of $\mathrm{T}_{1}$ and $\mathrm{T}_{2}$.

where $h_{i}$ is the unknown parameter (includes the constants of the correlation); $Y_{i m}$ is the $i^{\text {th }}$ observation from the $m^{\text {th }}$ measurement; $M$ and $N$ are the number of measurements and observations, respectively. $T_{i m}\left(h_{i}\right)$ is the calculated temperature obtained with the guessed value from the fast forward model.

The Bayesian framework is a combination of likelihood function, which is based on the mathematical model, and the prior information about the parameter to be estimated. With the help of measurements and the prior information, Bayesian framework exploits the posterior distribution to explore the sample space. The conditional probability of the parameters $\mathbf{P}$ given the measurements $\mathbf{Y}$, the posterior probability density function, can be obtained using Bayesian approach $[36,45,46]$. The Bayes theorem to connect the experimental data $\mathbf{Y}$ with the parameter $\mathbf{P}$ is given as

$$
\pi_{\text {posterior }}(\mathbf{P})=\pi(\mathbf{P} / \mathbf{Y})=\frac{\pi_{\text {prior }}(\mathbf{P}) \pi(\mathbf{Y} / \mathbf{P})}{\pi(\mathbf{Y})}
$$

where $\pi_{\text {posterior }}(\mathbf{P})$ is the posterior probability density function (PPDF) (conditional probability of the parameters

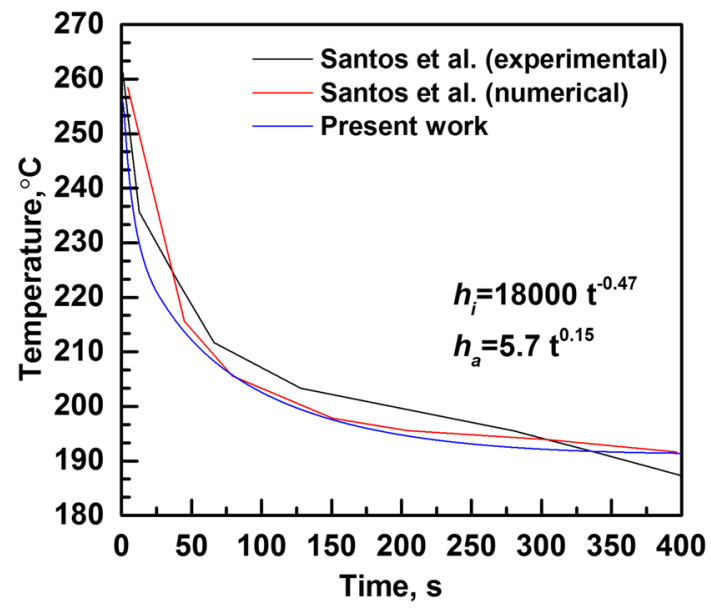

Figure 9. Validation of the forward model [42].

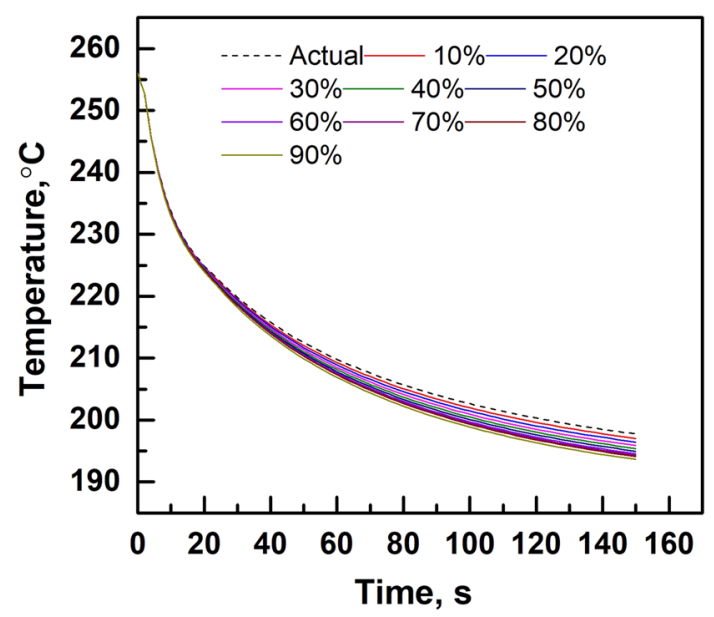

Figure 10. Temperature distribution at $\mathrm{T}_{1}$ for $\%$ change in values of $a$ in $h_{i}$ correlation.

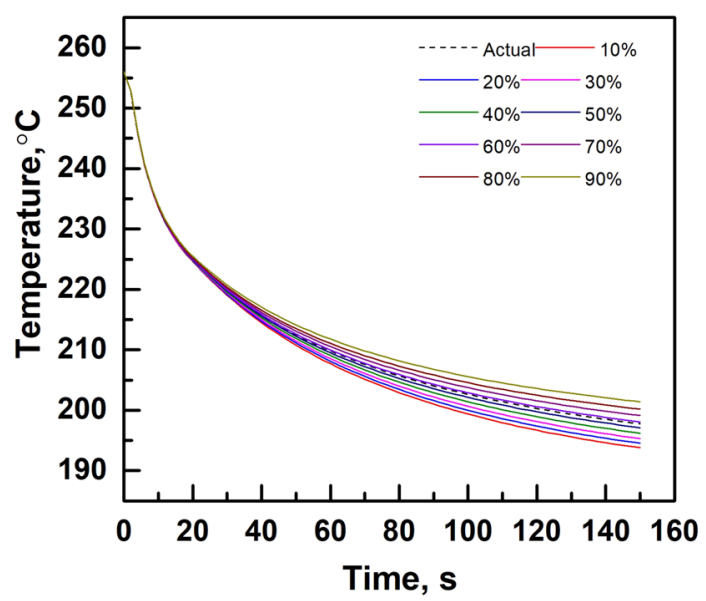

Figure 11. Temperature distribution at $T_{1}$ for $\%$ change in values of $b$ in $h_{i}$ correlation. 
Table 2. Estimated values of $a$ and $b$ using ANN-GA-LSM for different runs for exact temperature data.

\begin{tabular}{|c|c|c|c|c|c|c|}
\hline Run & $\begin{array}{c}a \\
(18000)\end{array}$ & $\begin{array}{l}\text { Absolute\% } \\
\text { error of } a\end{array}$ & $\begin{array}{c}b \\
(0.47)\end{array}$ & $\begin{array}{c}\text { Absolute\% } \\
\text { error of } b\end{array}$ & Time (s) & $\begin{array}{c}\text { Fitness } \\
\text { value }\end{array}$ \\
\hline 1 & 18091.42 & 0.507 & 0.471 & 0.212 & 86.1 & 0.01743 \\
\hline 2 & 18092.79 & 0.515 & 0.471 & 0.212 & 84.5 & 0.01743 \\
\hline 3 & 18090.86 & 0.504 & 0.471 & 0.212 & 82.3 & 0.01743 \\
\hline Average & 18091.69 & 0.509 & 0.471 & 0.212 & 84.3 & 0.01743 \\
\hline
\end{tabular}
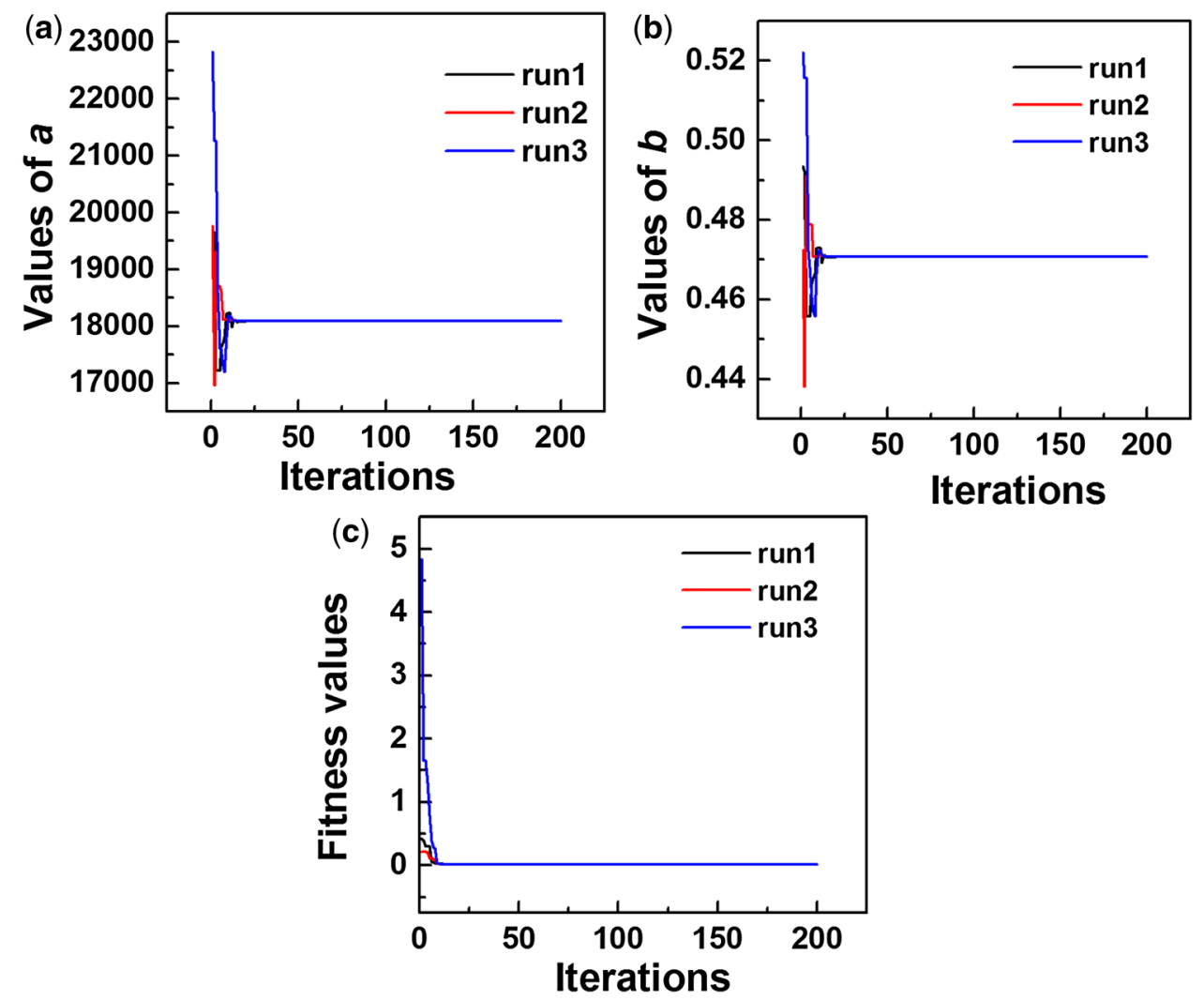

Figure 12. (a) Convergence of ' $a$ ' value. (b) Convergence of ' $b$ ' value. (c) Convergence of fitness values for exact temperature data using ANN-GA-LSM.

Table 3. Estimated values of $a$ and $b$ using ANN-GA-LSM for different runs for $\sigma=0.01 T_{\max }$ temperature data.

\begin{tabular}{lccccr}
\hline Run & $\begin{array}{c}a \\
(18000)\end{array}$ & $\begin{array}{c}\text { Absolute\% } \\
\text { error of } a\end{array}$ & $\begin{array}{c}b \\
(0.47)\end{array}$ & $\begin{array}{c}\text { Absolute\% } \\
\text { error of } b\end{array}$ & $\begin{array}{c}\text { Fitness } \\
\text { value }\end{array}$ \\
\hline 1 & 19389.55 & 7.719 & 0.497 & 5.75 & 894.84 \\
2 & 19376.83 & 7.649 & 0.497 & 5.75 & 115.2 \\
3 & 19400.96 & 7.783 & 0.497 & 5.75 & 105.45 \\
Average & $\mathbf{1 9 3 8 9 . 1 1 3}$ & $\mathbf{7 . 7 1 7}$ & $\mathbf{0 . 4 9 7}$ & $\mathbf{5 . 7 5}$ & 108.52 \\
\hline
\end{tabular}

$\mathbf{P}$ given the measurements $\mathbf{Y}), \pi(\mathbf{Y} / \mathbf{P})$ is likelihood function (the likelihood of different measurement outcomes $\mathbf{Y}$ with $\mathbf{P}$ given, which is obtained from the forward model), $\pi_{\text {prior }}(\mathbf{P})$ is the prior density (information about the unknown parameters which is available prior to the measurements) and $\pi(\mathbf{Y})$ is the probability density of the measurements (generally a normalizing constant). The posterior probability is given as 


$$
\text { posterior } \propto \text { prior } \times \text { likelihood } .
$$

Therefore, the posterior probability density function is directly proportional to the prior probability times likelihood function. $\mathbf{P}$ in Eq. (15) is the unknown parameter to be estimated and $\mathbf{Y}$ is the temperature vector. In general, the measurement errors are Gaussian random variables, with known means and covariances, and also the measurement errors are additive and independent. Using these hypotheses, the likelihood function can be expressed as Eq. (17) [36]:

$$
\begin{aligned}
& \pi(\mathbf{Y} / \mathbf{P})=(2 \pi)^{-\frac{M}{2}}|\mathbf{W}|^{-\frac{1}{2}} \\
& \quad \times \exp \left\{-\frac{1}{2}[\mathbf{Y}-\mathbf{T}(\mathbf{P})]^{T} \mathbf{W}^{-1}[\mathbf{Y}-\mathbf{T}(\mathbf{P})]\right\}
\end{aligned}
$$

where $M$ is the number of measurements and $\mathbf{W}$ is the covariance matrix of the measurement errors. The Gaussian prior can be given as

$$
\pi(\mathbf{P})=(2 \pi)^{-\frac{N}{2}}|\mathbf{V}|^{-\frac{1}{2}} \exp \left[-\frac{1}{2}(\mathbf{P}-\mu)^{T} \mathbf{V}^{-1}(\mathbf{P}-\mu)\right]
$$

where $\mu$ is the known mean and $\mathbf{V}$ is the co-variance matrix for $\mathbf{P}$. Therefore, the posterior probability density function becomes

$$
\begin{aligned}
& \pi(\mathbf{P} / \mathbf{Y})=(2 \pi)^{-\frac{M}{2}}|\mathbf{W}|^{-\frac{1}{2}} \\
& \quad \times \exp \left\{-\frac{1}{2}[\mathbf{Y}-\mathbf{T}(\mathbf{P})]^{\mathbf{T}} \mathbf{W}^{-\mathbf{1}}[\mathbf{Y}-\mathbf{T}(\mathbf{P})]\right\} \\
& \quad \times(2 \pi)^{-\frac{N}{2}}|\mathbf{V}|^{-\frac{1}{2}} \exp \left[-\frac{\mathbf{1}}{\mathbf{2}}(\mathbf{P}-\mu)^{\mathbf{T}} \mathbf{V}^{-\mathbf{1}}(\mathbf{P}-\mu)\right]
\end{aligned}
$$

Applying ln on both sides gives

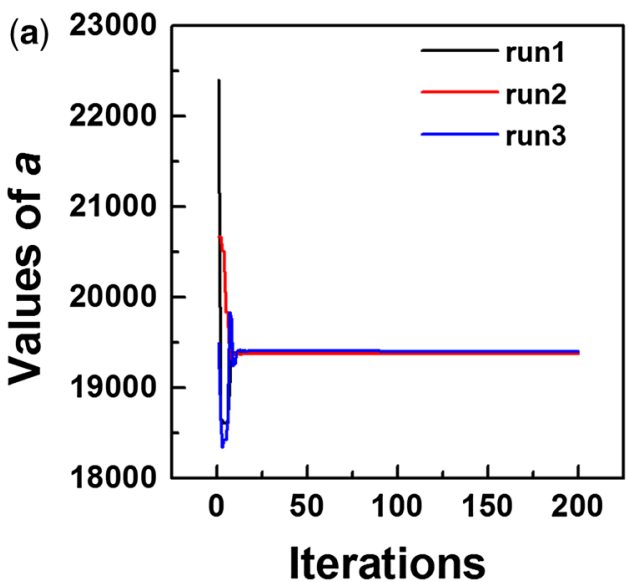

$$
\begin{aligned}
-\ln P P D F= & \sum_{m=1}^{M} \sum_{i=1}^{N} \frac{\left[Y_{i m}-T_{i m}\left(h_{i}\right)\right]^{2}}{2\left(M E \times T_{\max }\right)^{2}}+\frac{\left(a-\mu_{a}\right)^{2}}{2 \sigma_{a}^{2}} \\
& +\frac{\left(b-\mu_{b}\right)^{2}}{2 \sigma_{b}^{2}}+\frac{\left(M E-\mu_{M E}\right)^{2}}{2 \sigma_{M E}^{2}}
\end{aligned}
$$

where $h_{i}$ is the unknown parameter and $Y_{i m}$ is the $i^{\text {th }}$ observation from the $m^{\text {th }}$ measurement; $M$ and $N$ are the number of measurements and observations, respectively. $T_{i m}\left(h_{i}\right)$ is the calculated temperature obtained from the fast forward solution, $a$ and $b$ are the range of values generated by GA, $M E$ is the modelling error associated with the temperature measurement, $\mu_{a}=18000$ and $\mu_{b}=0.47 ; \sigma_{a}$ and $\sigma_{b}$ are taken as $0.01 \mu_{a}$ and $0.01 \mu_{b}$, respectively. Figure 5 shows an overview of the present work.

\section{Results and discussion}

Before attempting the inverse method, validation of inhouse code is performed by solving a benchmark problem using GA. Rosenbrock banana function [47] was considered as the benchmark problem, which is given by Eq. (21):

$$
f(x)=100\left(y-x^{2}\right)^{2}+(1-x)^{2}
$$

Table 4. Estimated values of $a$ and $b$ using ANN-GA-LSM for different runs for $\sigma=0.02 T_{\max }$ temperature data.

\begin{tabular}{lccccc}
\hline Run & $\begin{array}{c}a \\
(18000)\end{array}$ & $\begin{array}{c}\text { Absolute } \% \\
\text { error of } a\end{array}$ & $\begin{array}{c}b \\
(0.47)\end{array}$ & $\begin{array}{c}\text { Absolute\% } \\
\text { error of } b\end{array}$ & Time (s) \\
\hline 1 & 11392.7 & 36.70 & 0.3 & 36.17 & 120.2 \\
2 & 11392.7 & 36.70 & 0.3 & 36.17 & 99.5 \\
3 & 11392.7 & 36.70 & 0.3 & 36.17 & 110.8 \\
Average & $\mathbf{1 1 3 9 2 . 7}$ & $\mathbf{3 6 . 7 0}$ & $\mathbf{0 . 3}$ & $\mathbf{3 6 . 1 7}$ & $\mathbf{1 1 0 . 1 7}$ \\
\hline
\end{tabular}

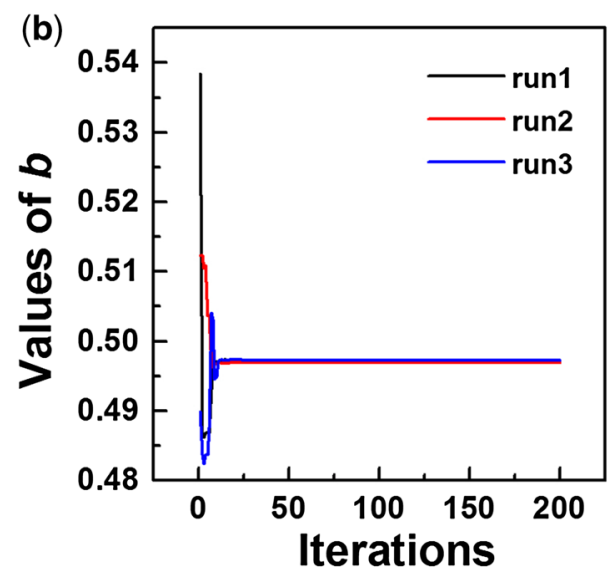

Figure 13. (a) Convergence of ' $a$ ' value. (b) Convergence of ' $b$ ' value for $\sigma=0.01 T_{\max }$ temperature data using ANN-GA-LSM. 
Table 5. Estimated values of $a$ and $b$ using ANN-GA-LSM for different runs for $\sigma=0.03 T_{\max }$ temperature data.

\begin{tabular}{lccccc}
\hline Run & $\begin{array}{c}a \\
(18000)\end{array}$ & $\begin{array}{c}\text { Absolute\% } \\
\text { error of } a\end{array}$ & $\begin{array}{c}b \\
(0.47)\end{array}$ & $\begin{array}{c}\text { Absolute\% } \\
\text { error of } b\end{array}$ & $\begin{array}{c}\text { Time } \\
(\mathrm{s})\end{array}$ \\
\hline 1 & 17005.28 & 5.526 & 0.3 & 36.17 & 104.3 \\
2 & 17949.17 & 0.282 & 0.31 & 34.04 & 101.2 \\
3 & 17584.88 & 2.306 & 0.307 & 34.68 & 107.5 \\
Average & $\mathbf{1 7 5 1 3 . 1 1}$ & $\mathbf{2 . 7 0 4}$ & $\mathbf{0 . 3 0 6}$ & $\mathbf{3 4 . 8 9}$ & $\mathbf{1 0 4 . 3}$ \\
\hline
\end{tabular}

A range of $x, y$ between -5 and 5 was chosen. Figure 6 shows the successful retrieval values of $x$ and $y$ from the inhouse GA code, proving the robustness, where the minimum of the banana function lies at $(1,1)$. Thus, the inverse code is validated and proved to be a robust method for the estimation purpose. Figure 7 shows the transient IHTC $\left(h_{i}\right)$ and chill-environment heat transfer coefficient values $\left(h_{a}\right)$ variation of pre-assumed values from Eq. (12). Using these pre-assumed values, the forward model is solved and the temperature distribution inside the casting and chill is obtained as shown in figure 8 . The $h_{i}$ possess higher values during the initial stages of the solidification due to the good contact of the molten metal and chill surface at the interface. Later due to the heat release from the liquid metal to the chill, an air gap is formed; hence the values of $h_{i}$ decrease. As the chill continuously receives heat, the temperature of the chill increases and the values of $h_{a}$ gradually increase. The temperature distribution at the sensor location

Table 6. Estimated values of $a$ and $b$ using ANN-GA-Bayesian framework for different runs for exact temperature data.

\begin{tabular}{|c|c|c|c|c|c|c|}
\hline Run & $\begin{array}{c}a \\
(18000)\end{array}$ & $\begin{array}{l}\text { Absolute\% } \\
\text { error of } a\end{array}$ & $\begin{array}{c}b \\
(0.47)\end{array}$ & $\begin{array}{l}\text { Absolute \% } \\
\text { error of } b\end{array}$ & Time (s) & $-\ln P P D F$ \\
\hline 1 & 18001.41 & 0.0078 & 0.469 & 0.21 & 85.6 & 0.002275 \\
\hline 2 & 18001.41 & 0.0078 & 0.469 & 0.21 & 88.74 & 0.002275 \\
\hline 3 & 18002.41 & 0.0133 & 0.469 & 0.21 & 94.15 & 0.002275 \\
\hline Average & 18001.74 & 0.0096 & 0.469 & 0.21 & 89.49 & 0.002275 \\
\hline
\end{tabular}
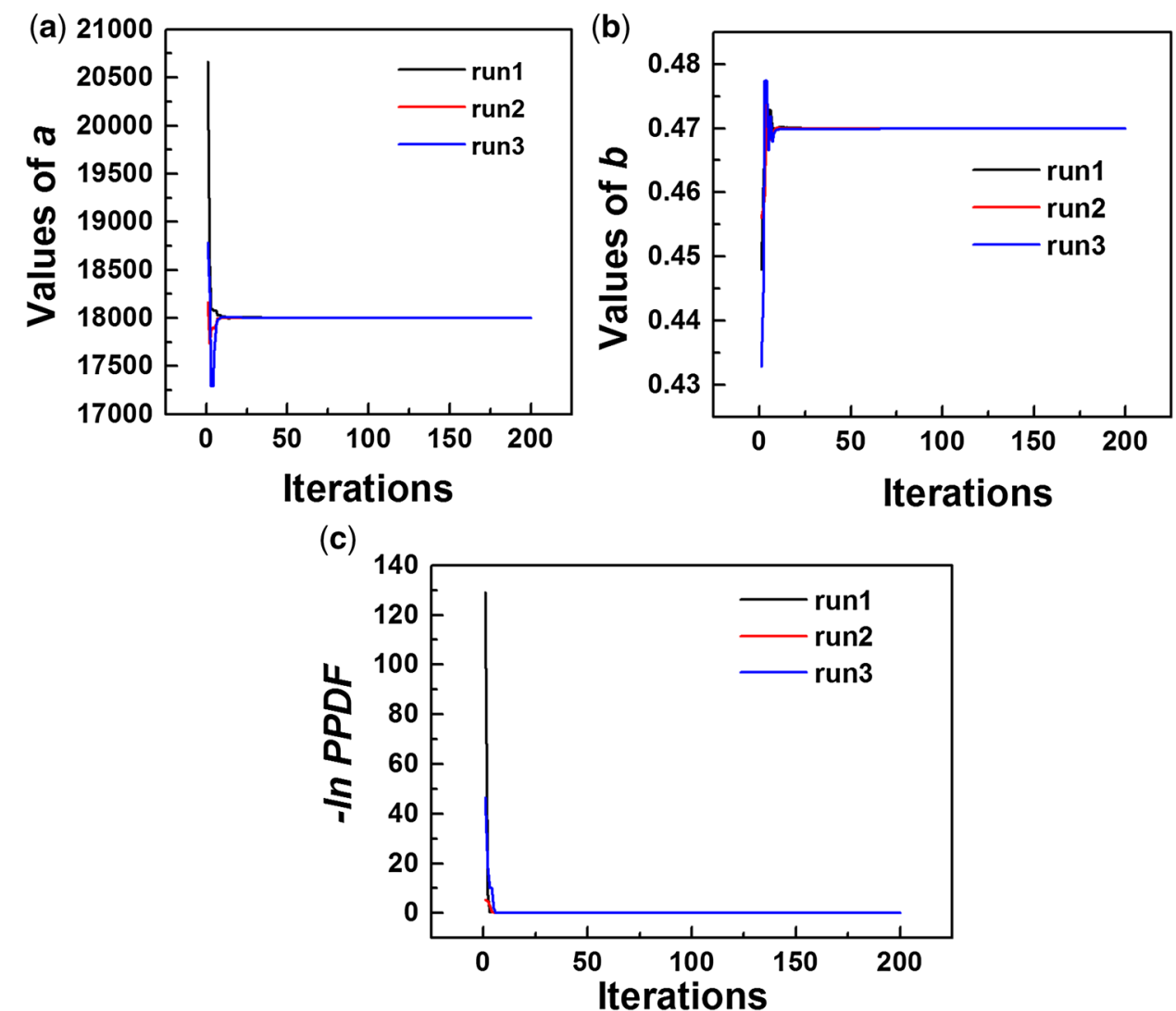

Figure 14. (a) Convergence of ' $a$ ' value. (b) Convergence of ' $b$ ' value. (c) Convergence of $-\ln P P D F$ for exact temperature data using ANN-GA-Bayesian framework. 
$20 \mathrm{~mm}$ inside the mold cavity used for the inverse analysis is validated as shown in figure 9.

Choosing an appropriate value of $h_{i}$ for the numerical simulation is the most important decision because a random or guess value of $h_{i}$ always results in different temperature distribution during the solidification. A common practice in industries is to use trial and error method to choose $h_{i}$. In order to show this, a sensitivity study at the sensor $T_{1}$ is carried out where a change of $10 \%$ from the actual value of constants of the $h_{i}$ correlation $a$ and $b$ is chosen and plotted in figures 10 and 11 .

Now the process of estimation of unknown parameters is carried out using GA. The input parameters for GA such as number of population $=20$, iterations $=200$ and mutation rate $=0.06$ were initialized. The range of the values of $a=[100030000]$ and $b=[0.30 .6]$ were selected based on the work of Santos et al [42], where a wealth of information is available on the solidification of $\mathrm{Sn}-\mathrm{Pb}$ alloys. The inverse estimation was performed on a 12-GB RAM, INTEL i5 Core, $1.70-\mathrm{GHz}$ computer. Three runs were carried out with the same initialized input parameters, and the estimated values are collected and reported in table 2. For the exact temperature data, ANN-driven GA provides good estimates of $a$ and $b$ with LSM as objective function. The average values $a=18091.69$ and $b=0.471$ were obtained with an absolute \% error of $a$ and $b$ as 0.509 and 0.212 , respectively. The minimum fitness value was found to be 0.01743 . The ANN-driven GA took around $83.4 \mathrm{~s}$, which shows a huge reduction in the computational cost compared with conventional model, i.e., without ANN.

Table 7. Estimated values of $a$ and $b$ using ANN-GA-Bayesian framework for different runs for $\sigma=0.01 T_{\max }$ temperature data.

\begin{tabular}{lccccccc}
\hline Run & $\begin{array}{c}a \\
(18000)\end{array}$ & $\begin{array}{c}\text { Absolute } \% \\
\text { error of } a\end{array}$ & $\begin{array}{c}b \\
(0.47)\end{array}$ & $\begin{array}{c}\text { Absolute } \\
\text { error of } b\end{array}$ & $M E$ & $\begin{array}{c}\text { Absolute\% } \\
\text { error of } M E\end{array}$ & Time (s) \\
\hline 1 & 17984.31 & 0.0871 & 0.4708 & 0.1702 & 0.0101 & 1 & 83.32 \\
2 & 17984.14 & 0.0881 & 0.4708 & 0.1702 & 0.0101 & 1 & 85.48 \\
3 & 17983.69 & 0.0906 & 0.4708 & 0.1702 & 0.0101 & 1 & 85.48 \\
Average & $\mathbf{1 7 9 8 4 . 0 4}$ & $\mathbf{0 . 0 8 8 6}$ & $\mathbf{0 . 4 7 0 8}$ & $\mathbf{0 . 1 7 0 2}$ & $\mathbf{0 . 0 1 0 1}$ & $\mathbf{1}$ & $\mathbf{8 4 . 7 6}$ \\
\hline
\end{tabular}
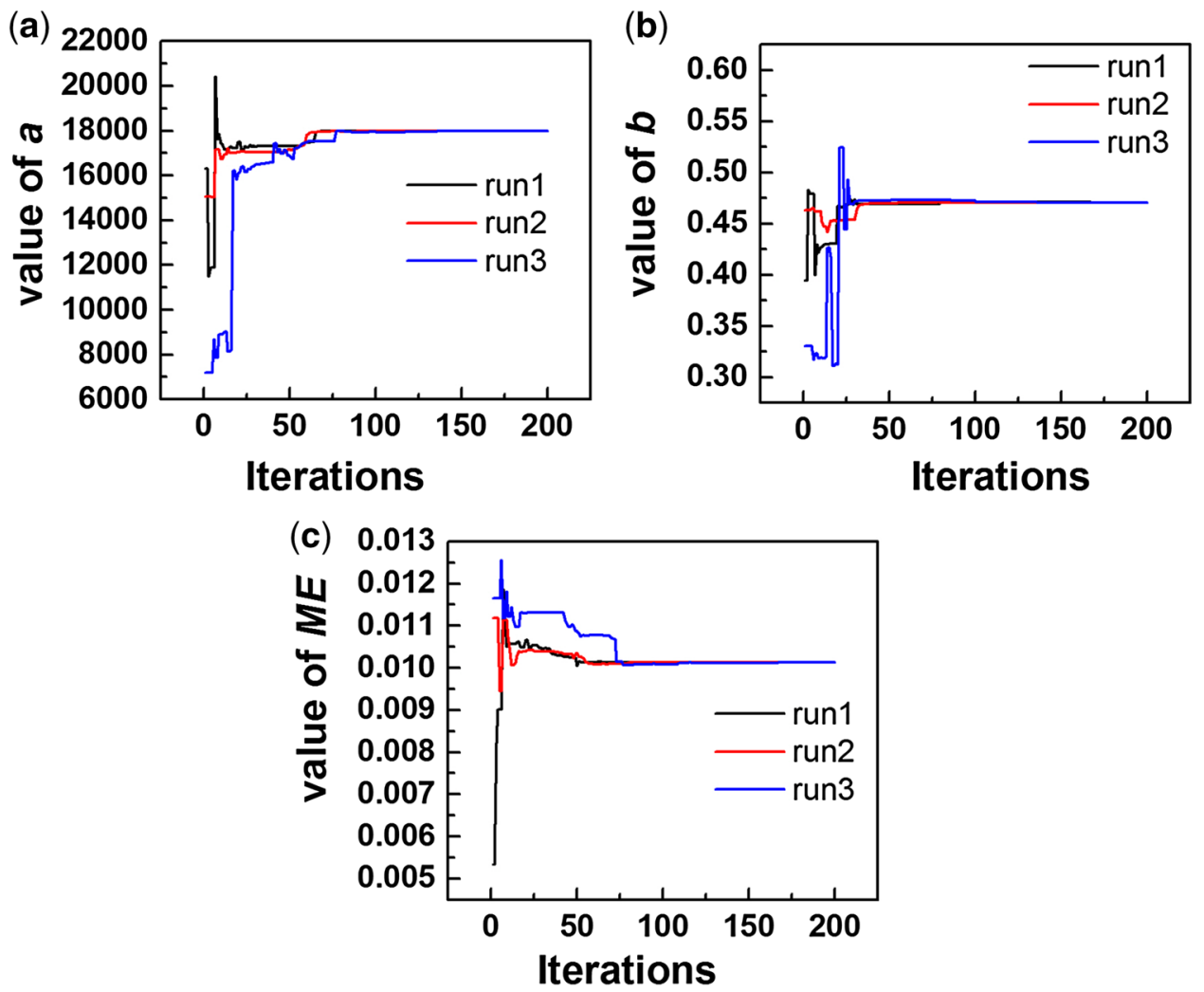

Figure 15. (a) Convergence of ' $a$ ' value. (b) Convergence of ' $b$ ' value. (c) Convergence of ' $M E$ ' value using ANN-GA-Bayesian framework for $\sigma=0.01 T_{\max }$ noisy temperature data. 
Figure 12(a) and (b) shows the estimation of values of $a$ and $b$ using LSM for exact temperature data, respectively. Figure 12(c) provides the corresponding fitness values convergence for exact temperature data using LSM.

The estimation is now extended to noisy temperature data with $\sigma=0.01 T_{\max }$; similarly three different runs are carried out and reported in table 3 . It was observed that the estimated values had a large deviation from the actual value with an absolute \% error of 7.717 and 5.75 for the estimated $a$ and $b$ values, respectively. The average fitness value was found to be 894.84. Figure 13(a) and (b) shows the convergence of $a$ and $b$ values for $\sigma=0.01 T_{\max }$ temperature data, respectively. Table 4 provides the details of the estimated unknown parameters for $\sigma=0.02 T_{\max }$ noise data.
The ANN-GA with LSM showed an unusual estimation with a very large absolute $\%$ error of 36 . Hence, in order to check the accuracy of estimation for larger noisy data, a Gaussian noise with $\sigma=0.03 T_{\max }$ is added for the exact temperature and the estimation is continued.

It was observed that for high noisy data, a good estimation was achieved for the retrieval of $a$ values with absolute \% error of 2.704 whereas for the value of $b$, there was again a huge deviation from the actual value of 0.47 as mentioned in table 5. The overall estimation with LSM using ANN-trained inverse estimation was time saving but an accurate estimation was not achieved.

In order to overcome the disadvantage of LSM, the objective function was replaced by Bayesian framework. As mentioned in Eq. (20), to estimate the unknown

Table 8. Estimated values of $a$ and $b$ using ANN-GA-Bayesian framework for different runs for $\sigma=0.02 T_{\text {max }}$ temperature data.

\begin{tabular}{|c|c|c|c|c|c|c|c|c|}
\hline Run & $\begin{array}{c}a \\
(18000)\end{array}$ & $\begin{array}{l}\text { Absolute \% } \\
\text { error of } a\end{array}$ & $\begin{array}{c}b \\
(0.47)\end{array}$ & $\begin{array}{l}\text { Absolute } \% \\
\text { error of } b\end{array}$ & $M E$ & $\begin{array}{l}\text { Absolute } \% \\
\text { error of } M E\end{array}$ & Time,s & $-\ln P P D F$ \\
\hline 1 & 18019.42 & 0.107 & 0.468 & 0.425 & 0.0203 & 1.5 & 88.53 & 86.99 \\
\hline 2 & 18019.43 & 0.107 & 0.468 & 0.425 & 0.0203 & 1.5 & 87.92 & 86.99 \\
\hline 3 & 18019.41 & 0.107 & 0.468 & 0.425 & 0.0203 & 1.5 & 88.47 & 86.99 \\
\hline Average & 18019.42 & 0.107 & 0.468 & 0.425 & 0.0203 & 1.5 & 88.3 & 86.99 \\
\hline
\end{tabular}
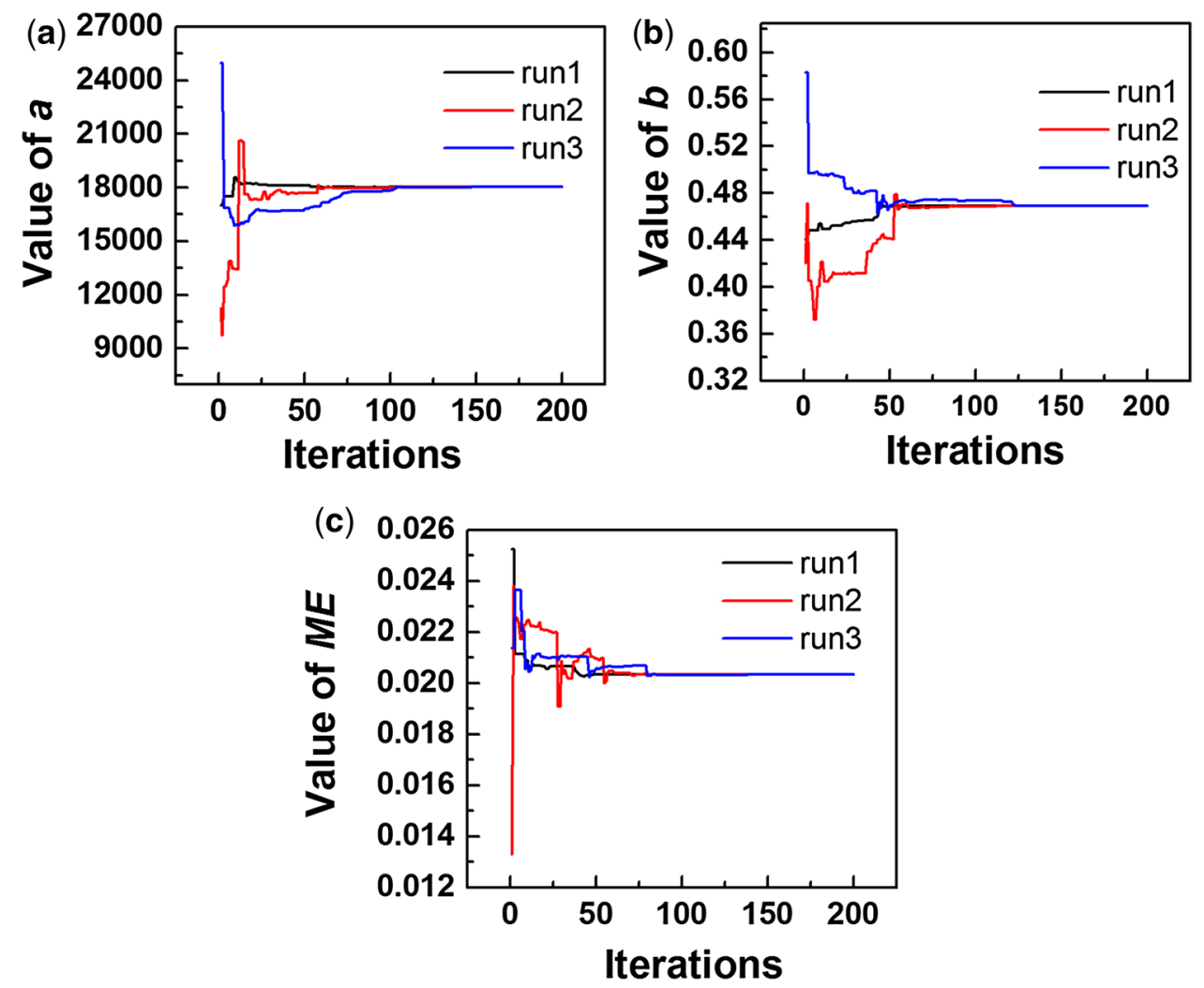

Figure 16. (a) Convergence of ' $a$ ' value. (b) Convergence of ' $b$ ' value. (c) Convergence of ' $M E$ ' value using ANN-GA-Bayesian framework for $\sigma=0.02 T_{\max }$ noisy temperature data. 
parameters, $-\ln P P D F$ was calculated. Initially, for the exact temperature data, the prior information about the noise is not considered. In order to achieve this, the range of values of $a=[100030000], b=[0.30 .6]$ was considered. Similar to the previous estimation, three runs with the same initial parameters using GA are carried out and the estimated values of $a$ and $b$ are reported in table 6. Compared to LSM, with ANN-GA-Bayesian framework the retrieved $a$ and $b$ values are very close to the actual value with absolute $\%$ error of 0.0096 and 0.21 , respectively. The - $\ln P P D F$ value is 0.002275 , which is found to be lesser compared with LSM. The convergence of $a$ and $b$ values and its fitness values are as shown in figure 14 .

Further, the estimation is carried out for noisy data with $\sigma=0.01 T_{\max }$. The range of values of $a=[100030000]$, $b=\left[\begin{array}{ll}0.30 .6 \\ 0\end{array}\right]$ and $M E=\left[\begin{array}{ll}0 & 0.4\end{array}\right]$ was chosen to solve using
GA. The advantage of Bayesian framework over LSM can be observed here. The Bayesian framework not only retrieves very accurate values of $a$ and $b$ but also provides an opportunity to estimate the $M E$ associated with the temperature measurements. As the Bayesian framework contains knowledge of priori information about the estimates, the method outperforms LSM, which is evident from the reported table 7 . The retrieved values have an error lesser than $2 \%$ compared to the actual values. The convergence of $a, b$ and $M E$ values is shown in figure 15. As the experimental temperature measurements are more prone to errors, the estimation is conducted for noisy temperature data with $\sigma=0.02 T_{\max }$. The retrieved unknown parameters reported in table 8 for the $\sigma=0.02 T_{\max }$ noisy temperature data show a good agreement with the actual values. The convergence of the corresponding unknown parameters is shown in figure 16. Similarly, the estimation was carried

Table 9. Estimated values of $a$ and $b$ using ANN-GA-Bayesian framework for different runs for $\sigma=0.03 T_{\text {max }}$ temperature data.

\begin{tabular}{ccccccccc}
\hline Run & $\begin{array}{c}a \\
(18000)\end{array}$ & $\begin{array}{c}\text { Absolute } \% \\
\text { error of } a\end{array}$ & $\begin{array}{c}b \\
(0.47)\end{array}$ & $\begin{array}{c}\text { Absolute\% } \\
\text { error of } b\end{array}$ & $M E$ & $\begin{array}{c}\text { Absolute\% } \\
\text { error of } M E\end{array}$ & $\begin{array}{c}\text { Time (s) } \\
-\ln P P D F\end{array}$ \\
\hline 1 & 18036.02 & 0.2 & 0.468 & 0.425 & 0.0305 & 1.67 & 97.8 \\
2 & 18036.05 & 0.2 & 0.468 & 0.425 & 0.0305 & 1.67 & 95.35 \\
3 & 18036.05 & 0.2 & 0.468 & 0.425 & 0.0305 & 1.67 & 95.46 \\
Average & $\mathbf{1 8 0 3 6 . 0 4}$ & $\mathbf{0 . 2}$ & $\mathbf{0 . 4 6 8}$ & $\mathbf{0 . 4 2 5}$ & $\mathbf{0 . 0 3 0 5}$ & $\mathbf{1 . 6 7}$ & $\mathbf{9 6 . 2}$ \\
\hline
\end{tabular}
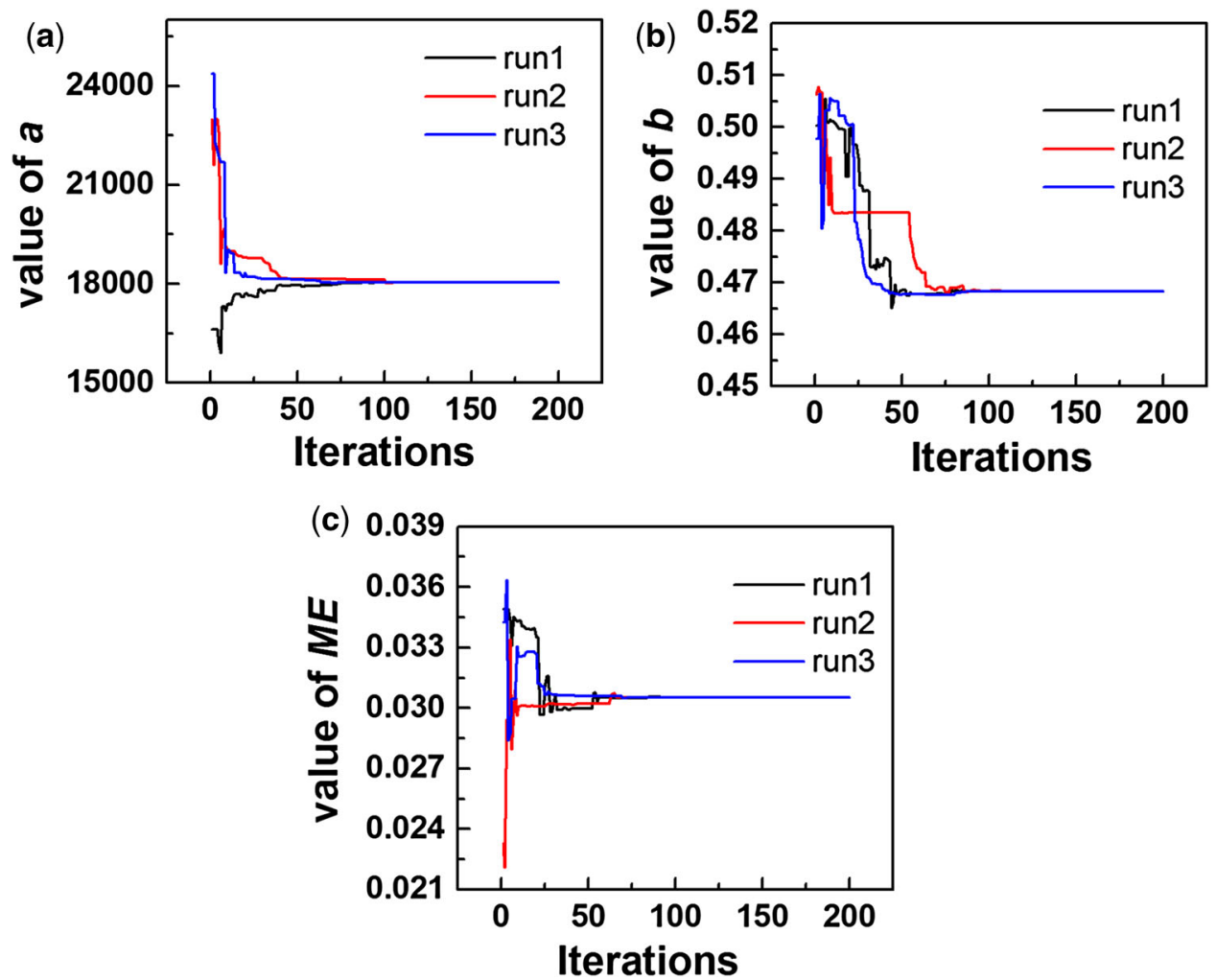

Figure 17. (a) Convergence of ' $a$ ' value. (b) Convergence of ' $b$ ' value. (c) Convergence of ' $M E$ ' value using ANN-GA-Bayesian framework for $\sigma=0.03 T_{\max }$ noisy temperature data. 

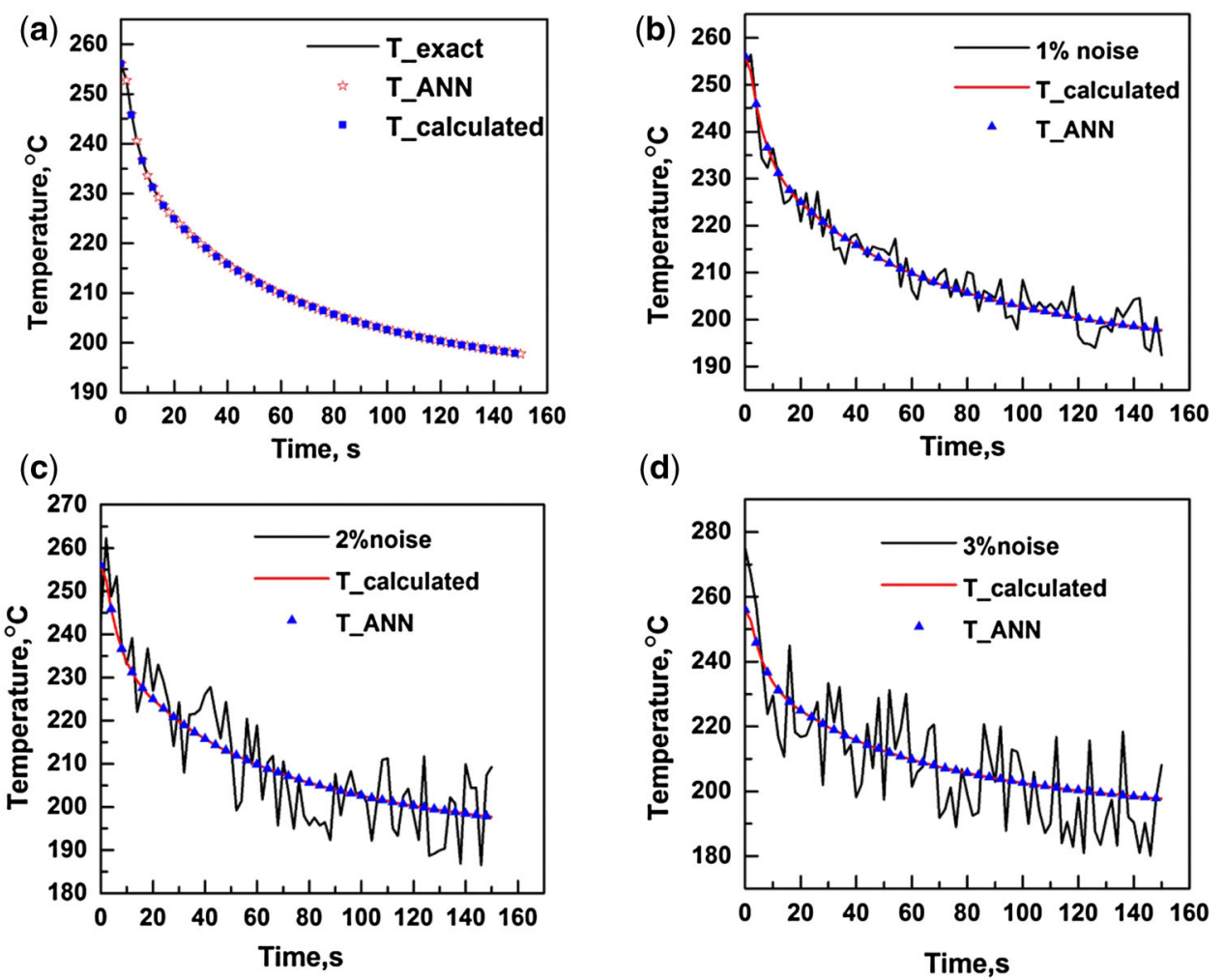

Figure 18. Comparison of temperature distribution obtained from the actual and retrieved values of $a$ and $b$ at $\mathrm{T}_{1} 20 \mathrm{~mm}$ inside the mold cavity sensor: (a) for exact temperature, (b) for $\sigma=0.01 T_{\max },(\mathbf{c})$ for $\sigma=0.02 T_{\max }$ and (d) for $\sigma=0.03 T_{\max }$.

out for a noisy temperature with $\sigma=0.03 T_{\max }$; as a result, GA in accordance with Bayesian is found to be an effective method for solving high noisy data as noted from table 9 . The corresponding convergence of $a, b$ and $M E$ values is shown in figure 17. The retrieved average values of $a$ and $b$ are used as an input for simulating forward model and ANN; the comparison of the obtained temperature distribution shown in figure 18 shows the noise handling capability of the inverse method.

\section{Conclusion}

An ANN-driven inverse estimation was attempted using GA. The forward model was solved to obtain the required temperature distribution for the solidification of $\mathrm{Sn}-$ $5 \mathrm{wt} \% \mathrm{~Pb}$ alloy. The major concern during inverse estimation of unknown parameters was the computational time. Therefore, a large data set, within the range of unknown parameters and corresponding temperatures, was created by solving the forward model; an ANN model was developed to reduce the computational time, which acted as a fast forward model. Though the ANN-GA with LSM was found to be good for the noiseless temperature data, the methodology failed to produce satisfactory results for the noise-added temperature data. Hence, the objective function was replaced with the Bayesian framework, thereby exploring the a priori information of the unknown parameters. The ANN-GA with Bayesian framework established effective results with the overall average absolute error less than 2\%; thus, it proved to be a competent and potent tool for the present inverse problem.

\section{List of symbols}

$C_{p} \quad$ specific heat, $(\mathrm{J} /(\mathrm{kgK}))$

$f_{s} \quad$ fraction of solid

$h_{a} \quad$ chill-environmental heat transfer coefficient, $\left(\mathrm{W} /\left(\mathrm{m}^{2} \mathrm{~K}\right)\right)$

$h_{i} \quad$ interfacial heat transfer coefficient, $\left(\mathrm{W} /\left(\mathrm{m}^{2} \mathrm{~K}\right)\right)$

$k \quad$ thermal conductivity, $(\mathrm{W} /(\mathrm{mK}))$

$l \quad$ latent heat

$M \quad$ number of sensors

PPDF posterior probability density function

$t \quad$ time, $\mathrm{s}$

$T_{l} \quad$ liquidus temperature, ${ }^{\circ} \mathrm{C}$

$T_{f} \quad$ fusion temperature, ${ }^{\circ} \mathrm{C}$

$T_{s} \quad$ solidus temperature, ${ }^{\circ} \mathrm{C}$

$T_{C} \quad$ casting surface temperature, ${ }^{\circ} \mathrm{C}$

$T_{M} \quad$ chill surface temperature, ${ }^{\circ} \mathrm{C}$

$K_{p} \quad$ partition coefficient

$\mathbf{T}(\mathbf{P}) \quad$ simulated temperatures, ${ }^{\circ} \mathrm{C}$

Y simulated measurements, ${ }^{\circ} \mathrm{C}$ 


\section{Greek}

$\sigma$ standard deviation of the prior Gaussian

$\rho$ density, $\left(\mathrm{kg} / \mathrm{m}^{3}\right)$

$\alpha$ thermal diffusivity, $\left(\mathrm{m}^{2} / \mathrm{s}\right)$

$\epsilon$ random variables

$\mu$ mean of prior Gaussian

\section{Subscripts \\ $f$ fusion \\ $l$ liquidus \\ $s$ solidus}

\section{References}

[1] Spinelli J E, Cheung N, Goulart P R, Quaresma J M and Garcia A 2012 Design of mechanical properties of Al-alloys chill castings based on the metal/mold interfacial heat transfer coefficient. Int. J. Therm. Sci. 51: 145-154

[2] Griffiths W D 1999 The heat-transfer coefficient during the unidirectional solidification of an Al-Si alloy casting. Metall. Mater. Trans. B 30: 473-482

[3] Ferreira I L, Spinelli J E, Nestler B and Garcia A 2008 Influences of solute content, melt superheat and growth direction on the transient metal/mold interfacial heat transfer coefficient during solidification of $\mathrm{Sn}-\mathrm{Pb}$ alloys. Mater. Chem. Phys. 111: 444-454

[4] Hallam C P and Griffiths W D 2004 A model of the interfacial heat-transfer coefficient for the aluminum gravity diecasting process. Metall. Mater. Trans. B 35: 721-733

[5] Gafur M A, Haque M N and Prabhu K N 2003 Effect of chill thickness and superheat on casting/chill interfacial heat transfer during solidification of commercially pure aluminium. J. Mater. Process. Technol. 133: 257-265

[6] Kayikci R, Griffiths W D and Strangeways C 2003 An ultrasonic technique for the determination of casting-chill contact during solidification. J. Mater. Sci. 38: 4373-4378

[7] Coates B and Argyropoulos S A 2007 The effects of surface roughness and metal temperature on the heat-transfer coefficient at the metal mold interface. Metall. Mater. Trans. B 38: $243-255$

[8] Loulou T, Artyukhin E A and Bardon J P 1999 Estimation of thermal contract resistance during the first stages of metal solidification process: II - experimental setup and results. Int. J. Heat Mass Transfer 42: 2129-2142

[9] Griffiths W D and Kawai K 2010 The effect of increased pressure on interfacial heat transfer in the aluminium gravity die casting process. J. Mater. Sci. 45: 2330-2339

[10] Ilkhchy A F, Jabbari M and Davami P 2012 Effect of pressure on heat transfer coefficient at the metal/mold interface of A356 aluminum alloy. Int. Commun. Heat Mass Transfer 39: $705-712$

[11] Ho K and Pehlke R D 1985 Metal-mold interfacial heat transfer. Metall. Mater. Trans. B 16: 585-594

[12] Kulkarni S and Radhakrishna D K 2011 Effect of casting/mold interfacial heat transfer during solidification of aluminium alloys cast in $\mathrm{CO}_{2}$-sand mold. Mater. Sci.Poland 29: 135-142
[13] Vasileiou A N, Vosniakos G C and Pantelis D I 2017 On the feasibility of determining the heat transfer coefficient in casting simulations by genetic algorithms. Procedia Manuf. 11: $509-516$

[14] Beck J V 1970 Nonlinear estimation applied to the nonlinear inverse heat conduction problem. Int. J. Heat Mass Transfer 13: $703-716$

[15] Rajaraman R and Velraj R 2008 Comparison of interfacial heat transfer coefficient estimated by two different techniques during solidification of cylindrical aluminum alloy casting. Heat Mass Transfer 44: 1025-1034

[16] Arunkumar S, Rao K S and Kumar T P 2008 Spatial variation of heat flux at the metal mold interface due to mold filling effects in gravity die-casting. Int. J. Heat Mass Transfer 51: 2676-2685

[17] Sun H C and Chao L S 2007 Analysis of interfacial heat transfer coefficient of green sand mold casting for aluminum and tin-lead alloys by using a lump capacitance method. $J$. Heat Transfer 129: 595-600

[18] Wood R L 1993 A comparison between the genetic algorithm and the function specification methods for an inverse thermal field problem. Eng. Comput. 10: 447-457

[19] Wood R L 1996 Genetic algorithm behaviour in the solution of an inverse thermal field problem. Eng. Comput. 13: 38-56

[20] Raudenský M, Woodbury K A, Kral J and Brezina T 1995 Genetic algorithm in solution of inverse heat conduction problems. Numer. Heat Transfer B-Fund. 28: 293-306

[21] Wong M D and Pao W K 2011 A genetic algorithm for optimizing gravity die casting's heat transfer coefficients. Expert. Syst. Appl. 38: 7076-7080

[22] Ranjbar A A, Ghaderi A, Dousti P and Famouri M 2011 A transient two-dimensional inverse estimation of the metalmold heat transfer coefficient during squeeze casting of $\mathrm{Al}-$ 4.5 wt\% Cu. Int. J. Eng. Trans. A 23: 273-286

[23] Dousti P, Ranjbar A A, Famouri M and Ghaderi A 2012 An inverse problem in estimation of interfacial heat transfer coefficient during two-dimensional solidification of Al 5\% Wt-Si based on PSO. Int. J. Numer. Methods Heat Fluid Flow 22: 473-490

[24] Vasileiou A N, Vosniakos G C and Pantelis D I 2015 Determination of local heat transfer coefficients in precision castings by genetic optimisation aided by numerical simulation. Proc. Inst. Mech. Eng. Part C: J. Mech. 229: 735-750

[25] Wang X, Wang Z, Liu Y, Du F, Yao M and Zhang X 2016 A particle swarm approach for optimization of secondary cooling process in slab continuous casting. Int. J. Heat Mass Transfer 93: 250-256

[26] Zhang L, Li L, Ju H and Zhu B 2010 Inverse identification of interfacial heat transfer coefficient between the casting and metal mold using neural network. Energy Convers. Manag. 51: 1898-1904

[27] Kumar M K, Vishweshwara P S, Gnanasekaran N and Balaji C 2018 A combined ANN-GA and experimental based technique for the estimation of the unknown heat flux for a conjugate heat transfer problem. Heat Mass Transfer 54: 3185-3197

[28] Kumar H and Gnanasekaran N 2018 A Bayesian inference approach: estimation of heat flux from fin for perturbed temperature data. Sadhana Acad. Proc. Eng. Sci. 43: 62

[29] Chanda S, Balaji C, Venkateshan S P and Yenni G R 2017 Estimation of principal thermal conductivities of layered 
honeycomb composites using ANN-GA based inverse technique. Int. J. Therm. Sci. 111: 423-436

[30] Ghadimi B, Kowsary F and Khorami M 2015 Heat flux online estimation in a locomotive brake disc using artificial neural networks. Int. J. Therm. Sci. 90: 203-213

[31] Lugon Jr J, Silva Neto A J and Santana C C 2009 A hybrid approach with artificial neural networks, Levenberg-Marquardt and simulated annealing methods for the solution of gas-liquid adsorption inverse problems. Inverse Prob. Sci. Eng. 17: 85-96

[32] Soeiro F J C P, Soares P O, Campos Velho H F and Silva Neto A J 2004 Using neural networks to obtain initial estimates for the solution of inverse heat transfer problems. In: Proceedings of the Inverse Problems, Design and Optimization Symposium, pp. 358-363

[33] Lugon Jr J and Silva Neto A J 2011 Solution of porous media inverse drying problems using a combination of stochastic and deterministic methods. J. Braz. Soc. Mech. Sci. Eng. 33: 400-407

[34] Udayraj, Mulani K, Talukdar P, Das A and Alagirusamy R 2015 Performance analysis and feasibility study of ant colony optimization, particle swarm optimization and cuckoo search algorithms for inverse heat transfer problems. Int. J. Heat Mass Transfer 89: 359-378

[35] Sui D S and Cui Z S 2008 Regularized determination of interfacial heat transfer coefficient during ZL102 solidification process. Trans. Nonferrous Met. Soc. China 18: 399-404

[36] Mota C A, Orlande H R, Carvalho M O M, Kolehmainen V and Kaipio J P 2010 Bayesian estimation of temperaturedependent thermophysical properties and transient boundary heat flux. Heat Transfer Eng. 31: 570-580

[37] Yan L, Yang F and Fu C 2009 A Bayesian inference approach to identify a Robin coefficient in one-dimensional parabolic problems. J. Comput. Appl. Math. 231: 840-850
[38] Somasundharam S and Reddy K S 2017 Inverse estimation of thermal properties using Bayesian inference and three different sampling techniques. Inverse Prob. Sci. Eng. 25: 73-88

[39] Deng S and Hwang Y 2006 Applying neural networks to the solution of forward and inverse heat conduction problems. Int. J. Heat Mass Transfer 49: 4732-4750

[40] Wang J and Zabaras N 2004 A Bayesian inference approach to the inverse heat conduction problem. Int. J. Heat Mass Transfer 47: 3927-3941

[41] Knupp D C, Naveira-Cotta C P, Orlande H R and Cotta R M 2013 Experimental identification of thermophysical properties in heterogeneous materials with integral transformation of temperature measurements from infrared thermography. Exp. Heat Transfer 26: 1-25

[42] Santos C A, Siqueira C A, Garcia A, Quaresma J M and Spim J A 2004 Metal-mold heat transfer coefficients during horizontal and vertical unsteady-state solidification of $\mathrm{Al}-\mathrm{Cu}$ and $\mathrm{Sn}-\mathrm{Pb}$ alloys. Inverse. Prob. Sci. Eng. 12: 279-296

[43] Goldberg D E and Holland J H 1988 Genetic algorithms and machine learning. Mach. Learn. 3: 95-99

[44] Ozisik M N and Orlande H R B 2000 Inverse heat transfer: fundamentals and applications. Boca Raton: CRC Press

[45] Gnanasekaran N and Balaji C 2011 A Bayesian approach for the simultaneous estimation of surface heat transfer coefficient and thermal conductivity from steady state experiments on fins. Int. J. Heat Mass Transfer 54: 3060-3068

[46] Gnanasekaran N and Balaji C 2010 An inexpensive technique to simultaneously determine total emissivity and natural convection heat transfer coefficient from transient experiments. Exp. Heat Transfer 23: 235-258

[47] Rosenbrock H H 1960 An automatic method for finding the greatest or least value of a function. Comput. J. 3: 175-184 